Mônica Karawejczyk

Pontifícia Universidade Católica do Rio Grande do Sul, Porto Alegre, RS, Brasil

\title{
O Feminismo em Boa Marcha no Brasill Bertha Lutz e a Conferência pelo Progresso Feminino
}

Resumo: O propósito deste artigo é descrever e analisar os passos iniciais da associação feminina fundada por Bertha Lutz, a Federação Brasileira pelo Progresso Feminino, bem como a sua primeira conferência, eventos ocorridos no ano de 1922. Adotando uma metodologia de estudo de caso, se quer verificar as estratégias aplicadas pelo grupo e que acabaram por consolidar uma imagem de representantes de um "bom" feminismo no Brasil.

Palavras-Chave: Bertha Lutz; Conferência pelo Progresso Feminino; Feminismo

Bertha Maria Júlia Lutz (1894-1976) foi uma das principais líderes à frente do movimento feminino organizado no Brasil. Em 1915, ela ingressou na Faculdade de Ciências, da Universidade de Paris, diplomando-se em março de 1918, sendo que, alguns meses depois, em setembro, já estava empregada como tradutora de inglês, francês e alemão no Instituto Oswaldo Cruz, lugar que ocupou até assumir o cargo de secretário do Museu Nacional, em 4 de setembro de 1919. A Federação Brasileira pelo Progresso Feminino (FBPF), associação fundada por ela, em 1922, é a mais reconhecida na ałuação em prol da emancipação feminina do início do século XX. Aliás, quando se fala nos primórdios do feminismo brasileiro, tanto o nome de Bertha como o ano de 1922 se sobressaem na historiografia.

O feminismo apregoado por Bertha passou a ser identificado, à posteriori, como "bem-comportado" (Céli Regina Jardim PINTO, 2003) e/ou "tático" (Rachel SOIHET, 2006). Contudo, na época da sua aparição no espaço público brasileiro, ela foi identificada como representante de um "bom" feminismo deixando entrever que haveria outros, perigosos, que deveriam ser evitados.

Ela procurou fundar uma associação, com um grupo específico de mulheres, para fazer com que as vozes femininas - em uníssono - fossem ouvidas pela sociedade. Para

\section{(c) (7)}

Esta obra está sob licença Creative Commons. 
atingir tal objetivo elas tiveram que assumir certas posições estratégicas para poder levar suas demandas para o debate público. Afinal, naquela época, "qualquer mudança no comportamento feminino era considerada não apenas uma ameaça à permanência dos padrões rigidamente atribuídos aos gêneros, mas, de modo geral, ao próprio 'bom funcionamento' da sociedade" (Elisabeth Juliska RAGO, 2007, p. 82). Em mais de uma ocasião, Bertha externou o desejo de se ter uma única voz em prol da emancipação feminina no Brasil, pois somente dessa forma, segundo sua percepção, a causa feminista seria elevada a um patamar em que conseguiria alcançar seus objetivos.

Entre as demandas femininas/feministas do início do século XX estão desde pedidos de educação de qualidade para as mulheres, condições de trabalho mais justas, acessos a cargos públicos até reivindicações sobre direitos civis e políticos. Tal feminismo, que nasceu no século XVIII e desenvolveu-se ao longo dos séculos XIX e XX, é mais conhecido pela alcunha de feminismo liberal (Luís Felipe MIGUEL; Flávia BIROLI, 2013, p.10). A percepção de Bertha e de seu grupo sobre tais demandas podem ser apreciadas na Conferência pelo Progresso Feminino, evento que, até o momento, pouco foi explorado pela historiografia. Pretende-se, neste artigo, salientar os passos iniciais da FBPF através da exposição da sua fundação e da sua primeira conferência com o intuito de (re)conhecer as estratégias aplicadas pelo grupo, que acabaram por consolidar a imagem de representantes do "bom" feminismo no Brasil.

\section{A Federação Brasileira das Ligas pelo Progresso Feminino}

O ano de 1922 foi agitado no Brasil com inúmeros eventos culturais e políticos, entre eles, a Semana de Arte Moderna (fevereiro); eleições para presidente (março) e vice-presidente (março e agosto)'; a fundação do Partido Comunista (março); o Levante dos 18 do Forte -a primeira das revoltas tenentistas (julho); a fundação da Federação Brasileira pelo Progresso Feminino (agosto); as comemorações do Centenário da Independência (setembro);O Congresso Jurídico Brasileiro (outubro); a Exposição Internacional (de setembro a dezembro), a posse de Artur Bernardes (novembro) e a Conferência pelo Progresso Feminino (dezembro).

Bertha, tão logo regressou da Europa, procurou organizar uma associação no Rio de Janeiro. Ela tinha uma ideia bem definida de como tal grupo deveria ser, como se pode acompanhar em uma de suas primeiras manifestações sobre a questão,

[...] uma sociedade de brasileiras que compreendessem que a mulher não deve viver parasitamente do seu sexo, aproveitando os instintos animais do homem, mas que deve ser útil, instruir-se e à seus filhos, e tornar-se capaz de cumprir deveres políticos que o futuro não pode deixar de compartilhar com ela (REVISTA DA SEMANA, 1918, p.19).

Ela consegue fundar tal sociedade em 1920, como relatou para Harriet Adams: "Como você sabe, tenho estado à espera de encontrar algum tipo de associação destinada a ajudar o movimento feminista no país, estimulando, consolidando e reunindo esforços pessoais nesse sentido. [...] Agora eu consegui ser bem-sucedida e a iniciei este ano" (Bertha LUTZ, 1920). ${ }^{2}$ A associação foi batizada como Liga pela Emancipação Intelectual da Mulher (LEIM) e concebida para estudar os diferentes aspectos do movimento feminista e lutar pelos direitos femininos. Entre as fundadoras encontramos nomes como: Isabel Imbassahy Chermont; Stella Guerra Duval e Jeronima Mesquita, fundadoras do Pró-Matre; Júlia Lopes de Almeida, escritora; Maria Lacerda de Moura, professora.

1 O vice-presidente eleito em março de 1922, Urbano Santos, faleceu em maio, antes da posse, sendo convocadas novas eleições que ocorreram no mês de agosto, tendo sido eleito Estácio Coimbra.

${ }^{2}$ Todo o material do Fundo FBPF foi pesquisado no Arquivo Nacional, em maio de 2010. 
Yolanda Lobo (2010) descreve o grupo que se reuniu em torno da Liga como composto por mulheres cultas e ricas, pertencentes à elite carioca. Teresa Cristina de Novaes Marques (2016, p.23) relata que "Bertha associou-se a mulheres com bom trânsito político e sobrenomes ilustres" e, Branca Alves, afirma que a LEIM era

[...] composta por um grupo pequeno de mulheres que se conheciam entre si [...] e que pertenciam a famílias da burguesia. A partir da sua posição de esposas, filhas, amigas de homens da classe dominante, tinham acesso aos centros de poder [...]. Encontravamse em reuniões sociais com pessoas que podiam influenciar a causa (Branca Moreira ALVES, 1980, p.105).

Sobre a origem social das associadas da Liga destaco que, se em um primeiro momento, as que fizeram parte do grupo eram, na sua maioria, oriundas da elite econômica e/ou intelectual do país, não tardou para que mulheres de outras classes sociais fossem contatadas para fazerem parte do movimento. Como exemplo desse tipo de atitude podese citar uma listagem encontrada no fundo da FBPF que mostra a diversidade de atividades das mulheres contatadas para fazer parte da entidade tais como: advogadas, médicas, costureiras, datilógrafas, empregadas do comércio, confeiteiras, estudantes, escritoras, funcionárias públicas, professoras, modistas, professoras de piano e donas de casa (CONTROLE, 1934). Mulheres que, apesar de suas diferenças, uniram-se em torno de um mesmo objetivo para fazer valer os seus direitos e dar maior legitimidade para as suas reivindicações.

Além de se cercar de pessoas influentes, Bertha também procurou dar visibilidade às demandas do grupo através do envio de informes para a imprensa. Tal estratagema foi aplicado tanto na busca de aliados quanto uma forma de divulgação da associação. Desde a fundação, é possível encontrar as associadas partindo para a ação através do envio de telegramas para os políticos, reunindo-se com pessoas de destaque na sociedade e elaborando palestras com o intuito de apresentar a associação e as suas reivindicações. Também desde o início, a Liga procurava fazer pressão junto aos políticos para a aprovação das demandas femininas, de modo que a posição social das associadas pode ter facilitado a aceitação e a inserção da LEIM na sociedade; afinal, ao pertencer ao mesmo círculo social, elas conseguiam expor diretamente a sua causa para os homens de poder. De modo que divirjo da conclusão de June Hahner (2003) de que a LEIM não passava de um grupo de estudos sem conotações práticas.

Em dezembro de 1919, o senador Justo Chermont apresentou um projeto solicitando o voto para mulheres alfabetizadas maiores de 21 anos, Bertha declarou, para Branca Moreira Alves, que foi essa tentativa que a fez tomar a atitude fundar a LEIM (ALVES, 1980, p. 104). O projeto recebeu parecer favorável da Comissão de Constituição e Diplomacia, em 11 de maio de 1921, sendo aprovado em $1^{a}$ discussão em 8 de junho, desde então, ficou à espera da $2^{a}$ discussão para entrar em vigor (Mônica KARAWEJCZYK, 2013). Em 1921, Bertha passou a ser uma presença constante no Parlamento e chegou a se envolver pessoalmente na elaboração de uma emenda em prol do sufrágio feminino, dos deputados Nogueira Penido e Bethencourt Filho (LUTZ, 1921). Mostrando o prestígio que estava angariando no governo, ela foi convidada para participar de uma das reuniões da Comissão de Constituição e Justiça que estava ponderando sobre a questão do sufrágio feminino (O PAIZ, 11/1 1/1921, p. 6). A partir de então, a luta pela aprovação do sufrágio feminino passou a ocupar cada vez mais as atenções do grupo, sendo, inclusive, uma das justificativas elencadas por Bertha Lutz, à posteriori, para justificar a fundação da LEIM.

Nesse sentido, pode-se compreender a veiculação de um manifesto, lançado pela Liga, em fevereiro de 1922, sobre as eleições presidenciais. O manifesto inicia com as palavras: 
"Brasileiras! - não está longe o dia em que a nós também será dado o primordial direito de cidadania e de influir diretamente na vida política do nosso país" (CORREIO DA MANHÃ, 18/ 02/1922, p. 3) e, enquanto esse dia não chegava, solicitavam o apoio de todas para fazerem propaganda em prol da eleição dos candidatos Nilo Peçanha e J.J. Seabra - candidatos ao cargo de presidente e vice-presidente da República. Nilo Peçanha defendia o voło feminino desde o início do período republicano, tendo sido um dos deputados que apoiaram a causa em 1890, quando da feitura da nova Constituição. Artur Bernardes, outro candidato ao cargo de presidente, por sua vez, declarava-se avesso à possibilidade de se estender o voto para as brasileiras (KARAWEJCZYK, 2013, p.213). Tal ato evidencia mais uma das estratégias da Liga- 0 apoio explícito aos políitcos que se pronunciassem favoráveis as demandas femininas.

Desde a fundação da LEIM, Bertha, como presidente da entidade, procurou grupos femininos internacionais, tais como: National Union of Societies for Equal Citizenship, International Woman Suffrage Alliance, Alianza Uruguaya para el Sufragio Feminino, Leslie Woman Suffrage Comission, National League of Women Voters, National American Woman's Suffrage Association, tanto em busca de informações e orientações quanto em uma tentativa de dar legitimidade e visibilidade à Liga. Assim, ela passou a se corresponder e a se associar a grupos internacionais que lutavam em prol da emancipação feminina. Nesse sentido a presença da presidenta da LEIM na Conferência Pan-Americana de Mulheres, em julho de 1922, foi decisiva para os rumos do movimento organizado feminino no Brasil. Como veremos, tal participação selou o fim da Liga e estimulou a vinculação do grupo de Bertha ao movimento feminista estadunidense.

\subsection{Adequando a associação}

Desde os primeiros dias do mês de janeiro de 1922, a imprensa divulgava matérias sobre a Primeira Conferência Pan-Americana de Mulheres, que ocorreria na cidade de Baltimore (EUA), entre os dias 20 a 23 de julho, patrocinado pela National League of Women Voters, uma divisão da National Woman Suffrage Association (NAWSA), associação estadunidense fundada em 1868, na cidade de New York, vinculada ao movimento abolicionista e sufragista (Sheila ROWBOTHAM, 1997, p.39).

A participação de Bertha Lutz no evento foi um dos fatores que mudaram o rumo do movimento organizado feminino no Brasil. Desde então, ela passou a adequar os propósitos da Liga aos desígnios internacionais e a receber apoio de uma das suas líderes - Carrie Chapman Catt. ${ }^{3}$ June Hahner salienta que foi nessa visita que Bertha "transformou sua visão do movimento feminino. O modelo que lá encontrou pareceu-lhe mais apropriado ao Brasil do que o da Europa, que, vez por outra, resultava em algumas ações violentas" (HAHNER, 2003, p. 297-298). Após a passagem de Bertha pelos Estados Unidos, ela passou a ser nominada, pelos periódicos, como "a 'leader' mais autorizada do feminismo no Brasil" (O IMPARCIAL, 04/08/1922, p.3) que viria a conduzir o movimento organizado feminino para "uma orientação salutar" (A NOITE, 05/08/1922, p. 1). Ela também passou a ser apresentada como a pessoa mais indicada para orientar um "são movimento que visa o progresso feminino" no Brasil (O PAIZ, 30/08/1922, p. 6).

Os jornais da capital federal informaram que a conferência nos EUA iria reunir um grupo de importantes senhoras de influência e, entre os temas a serem abordados no evento mereceram destaque o bem-estar das crianças, a questão do trabalho feminino

${ }^{3}$ Carrie Chapman Catt (1859-1947) presidiu a NAWSA de 1900 a 1904, passando a organizar a área de New York, onde residia, até retornar à presidência da entidade para a gestão de 1915-1920. Ela estava à frente da associação quando da aprovação da $19^{a}$ emenda que assegurou o voto às mulheres, quando se afastou da associação para se dedicar aos movimentos internacionais, como a International Alliance of Women e a League of Women Voters, entidades que ajudou a fundar.

4 Revista Estudos Feministas, Florianópolis, 26(2): e49845 
nas indústrias, o tráfico de mulheres, a educação feminina e o estatuto político e civil das mulheres. A associação idealizadora da conferência foi descrita como

[...] uma sociedade que tem por fim educar as mulheres para serem cidadãs inteligentes, e usar do seu voto o melhor possível e apoiar os melhoramentos a introduzir-se na legislação. É composta de Ligas estaduais, que se acham funcionando em cada um dos 48 Estados da União (A NOITE, 02/01/1922, p.1).

A escolha de Bertha, como representante oficial do governo brasileiro, foi saudada com palavras elogiosas pelos periódicos. No regresso dos EUA, Bertha, em entrevista, descreveu a conferência, destacando que lá estiveram

[...] reunidas representantes oficiais de 22 países dos 24 que constituem o Novo Mundo, 200 mulheres latino-americanas, canadenses, senhoras membros do Parlamento, lady Astor, a encantadora deputada da Inglaterra, membro do Parlamento, e as 1600 delegadas dos ramos estaduais da Liga de Women Voters (A NOITE, 05/08/1922, p. 1).

Segundo a percepção de Bertha:

A Conferência de Baltimore, [...] teve uma significância tão profunda que não hesito em considera-la um acontecimento verdadeiramente histórico. Terá por consequência apressar a evolução das mulheres nos países latino-americanos, e evitar os erros de tática, e contribuirá para imprimir-lhe uma orientação salutar, pois o movimento nos Estados Unidos tem sido sempre muito digno e completamente alheio aos métodos violentos empregados em alguns dos países europeus [...]. (idem).

Bertha procurou salientar que muito aprendeu com a sua participação na conferência. Graças aos ensinamentos do movimento estadunidense, poder-se-ia, no Brasil, evitar os erros de tática, contribuir para imprimir uma orientação salutar ao movimento feminino e apressar a evolução das mulheres. Outro destaque da conferência foi a fundação da Associação Pan-Americana de Mulheres, para a qual Carrie Catt foi convidada para assumir a presidência e Bertha, indicada como vice-presidente geral. Em 1925 a Associação foi rebatizada para União Interamericana de Mulheres, sendo Bertha eleita a sua nova presidente (O IMPARCIAL, 12/05/1925, p.5). Inspirando-se nos modelos das associações femininas estadunidenses, e em especial, da NAWSA, as delegadas latinas se comprometeram a fundar "uma associação nacional em cada um dos países da América, sendo, esta subdividida em associações estaduais" (A NOITE, 05/08/1922, p. 2). Entre as metas da Associação destacavam-se: o aprimoramento do ensino para as mulheres, medidas legislativas destinadas à proteção feminina, a aprovação do voto feminino e o estreitamento de relações entre as mulheres de todos os países da América. Bertha aproveitou a ocasião para apresentar a LEIM como a filial brasileira da Associação Pan-americana, pois segundo suas palavras:

A Liga Brasileira Nacional já está constituída; brevemente estarão constituídos diferentes ramos estaduais e municipais. A sra Catt, [...] virá retribuir a visita a Baltimore no correr do ano próximo e percorrerá a América do Sul. Organizarei então uma conferência para recebê-la (A NOITE, 5/08/1922, p. 1-2).

Em nove de agosto já se encontram finalizadas as providências para adequar a Liga à sua nova posição, sendo esta data considerada como a fundação oficial da FBPF. Para Carrie Catt, Bertha assegurou:

A filial brasileira da Associação Pan-americana começou [...]. Nós reformamos a Constituição da Liga para a Emancipação da Mulher e fizemos dela a Liga Brasileira para o Progresso da Mulher, achamos melhor traduzir por 'Progresso', pois alguns tem medo da palavra Emancipação (LUTZ, 1922). 
Assim Bertha transforma a LEIM na filial brasileira da Associação Pan-Americana e começa a dividir parte das responsabilidades e dúvidas na condução do movimento organizado feminino com Carrie Catt, com quem viria a manter uma prolífica troca de missivas ao longo dos anos. Uma das primeiras ações conjuntas, Bertha-Carrie, ainda nos Estados Unidos, foi a feitura de um novo estatuto para a liga brasileira, aos moldes da NAWSA. Por esse estatuto, os objetivos da entidade passaram a ser: a emancipação feminina em todos os níveis desde a promoção da educação até a proteção às mães e a infância; a proteção para o trabalho feminino; a orientação para profissões; a conquista de direitos civis e políticos e a manutenção da paz mundial. Outra ação conjunta entre elas foi o planejamento e a execução da conferência no Brasil. Bertha destacou, para Branca Alves, que teve a ideia de fazer a conferência durante sua estada nos Estados Unidos, sendo que, na ocasião, Carrie Catt teria afirmado:

'Se você fizer um Congresso eu vou...' Eu perguntei a ela como se fazia um congresso, e ela disse: 'Vocês fazem assim: vocês convidam um político de proeminência para a sessão de abertura e outro para a sessão de encerramento. Nós dirigimos, eu falo, você fala, mas precisa ter um homem de projeção para dar importância (ALVES, 1980, p.111).

Assim, tão logo retornou para o Brasil, Bertha procurou expandir o campo de ação da associação, fundando filiais e, no mesmo dia em que transformou a LEIM na Liga Nacional pelo Progresso Feminino, fundou "a Liga do Distrito Federal e três dias depois a Liga Estadual para o Estado do Rio de Janeiro na capital da mesma, Niterói” (LUTZ, 1922). Em novembro já se encontram filiais nas cidades de São Paulo e Belo Horizonte e, em finais de dezembro, ocorre o primeiro congresso da entidade na capital federal. A associação foi rebatizada para Federação das Ligas pelo Progresso Feminino, nome que perdurou até meados de 1924, sendo então simplificada para Federação Brasileira pelo Progresso Feminino.

Na mesma época também foi providenciada a feitura de um hino próprio, a ser executado no início de todas as reuniões do grupo. A letra de Maria Eugenia Celso evoca um paradoxo, a elegia do papel de mãe como sendo o ideal feminista, como se pode acompanhar nas suas estrofes:

Desde a origem das coisas no mundo. Sempre foi meu mais alto labor. Sendo Mãe dar um gesto fecundo. As crianças e as Mães todo amor. Todas juntas na conquista. Deste novo e sagrado mister. Que é a essência do ideal feminista. Tudo à mulher, pela mulher! (Hino Feminista, 1922).

Tal elegia evidencia uma das imagens recorrentes na época, a da figura da mãe, que tenderia a absorver todas as outras e mesmo as sufocar. Ao dar centralidade para o papel da mãe elas também acabaram evocando imagens quase sempre associadas à da mulher redentora ou, de modo mais específico, à da mãe redentora que salvaria a República e moralizaria a política (Michelle PERROT, 1988).

Bom destacar que, na época, em questão, o papel da mulher na família era central na sociedade e sofreu poucas contestações pelo movimento feminino organizado. No Brasil, Maria Lacerda de Moura era uma das poucas mulheres que ousavam denunciar a opressão a que eram submetidas as mulheres (Miriam Lifchitz Moreira LEITE, 2005). Soihet (1996) salienta que nem Bertha e nem suas colaboradoras questionaram o fato de se atribuir às mulheres a total responsabilidade pelas atividades domésticas e pela socialização dos filhos, fato este que pode ser constatado na letra do hino da associação. Tanto as associadas da FBPF quanto outras mulheres da época consideravam o espaço doméstico como próprio da mulher. Flávia Biroli, neste sentido, esclarece que, desde a modernidade, 
[...] a esfera pública estaria baseada em princípios universais, na razão e na impessoalidade, ao passo que a esfera privada abrigaria as relações de caráter pessoal e íntimo. [...] Papéis atribuídos a elas [...], como a dedicação prioritária à vida doméstica e aos familiares, colaboraram para que a domesticidade feminina fosse vista como um traço natural e distintivo, mas também como um valor a partir do qual outros comportamentos seriam caracterizados como desvios. A natureza estaria na base das diferenças hierarquizadas entre os sexos (BIROLI, 2014, p.32).

Carole Pateman explicita que o sistema patriarcal foi baseado no apelo a uma suposta natureza que determinaria a função natural de cada um dos gêneros, prescrevendo - lugar de atuação de cada um: para as mulheres o espaço privado, justificado pela função biológica particular das mulheres de procriar e de gerar uma nova vida e, para os homens, as funções públicas. Assim

[...] no momento em que o feminismo surge como movimento social e político organizado, em meados do século XIX, o argumento da natureza havia sido aprimorado à doutrina das esferas separadas; homens e mulheres, alegava-se, tinham naturalmente lugares sociais distintos, mas complementares e igualmente valiosos (Carole PATEMAN, 2013, p.66).

Por outro lado, Joan Scott dá ênfase para a ambiguidade das próprias mulheres que, em busca de apoio para suas demandas, acabaram reforçando o papel maternal e doméstico da mulher no espaço privado. A autora, de forma muito apropriada, nomeia esse dilema como paradoxal e declara:

Quando se legitimava a exclusão com base na diferença biológica entre o homem e a mulher, estabelecia-se que a 'diferença sexual' não apenas era um fato natural, mas também uma justificativa ontológica para um tratamento diferenciado no campo político e social. [...] [Assim] esse paradoxo - a necessidade de, a um só tempo, aceitar e recusar a 'diferença sexual' - permeou o feminismo como movimento político por toda a sua longa história (SCOTT, 2002, p.26 e 27).

Ellen DuBois (1998) também destaca esse ponto ao apresentar os primórdios do movimento sufragista estadunidense. Para DuBois ao conceber/aceitar a centralidade do papel feminino no seio familiar, as sufragistas procuravam reformar as regras dessa sociedade, que as colocavam em franca desvantagem com os homens, e não contestar as raízes patriarcais da sociedade, sendo esta uma preocupação das feministas de outras gerações. Dessa forma, destaca-se, que uma das diferenças entre

[...] as primeiras feministas e sufragistas e as feministas contemporâneas é que quase todas, no século XIX, aceitavam a doutrina das esferas separadas [...]. Além disso, tanto antissufragistas mais fervorosos quanto sufragistas veementes concordavam em que as mulheres eram mais fracas [fisicamente], mas superiores moralmente e mais virtuosas, do que os homens (PATEMAN, 2013, p.66).

Assim a elegia à maternidade no hino de uma associação, como a FBPF, que lutava por novos espaços de sociabilidade para as mulheres no mundo público, pode ser melhor compreendida se percebida/analisada na sua época. O próximo passo para divulgação da nova associação foi a feitura da sua primeira conferência. Segundo a imprensa, ela foi elaborada para "comemorar o centenário da independência do Brasil e deliberar sobre alguns dos problemas mais importantes para a população feminina do nosso país" (O PAIZ, 17/12/1922, p. 5). Em dezembro de 1922 faziam parte da diretoria da FBPF: como presidente de honra, Julia Lopes de Almeida; presidente, Bertha Lutz; $1^{a}$ vice-presidente, Stella Guerra Duval; $2^{a}$ vice-presidente Jeronyma de Mesquita; $3^{a}$ vice-presidente, Margarida Lopes de Almeida; secretária geral, Valentina Biosca, e tesoureira, Corina Barreiros. 


\section{A Conferência pelo Progresso Feminino}

A Conferência pelo Progresso Feminino aconteceu no edifício Syllogeu, do Instituto dos Advogados, no centro do Rio de Janeiro, de 19 a 23 de dezembro. A Federação Brasileira das Ligas pelo Progresso Feminino se inspirou na Conferência Pan-Americana para planejar seu primeiro evento. Apesar de ser a primeira conferência da Federação, não era o primeiro evento que a LEIM elaborava. Quando da fundação da LEIM, um conjunto de cartas - preservadas no fundo da FBPF no Arquivo Nacional - atesta que Bertha Lutz patrocinava palestras na capital federal e que Maria Lacerda de Moura, descrita como "membro ativo" da LEIM, foi convidada por Bertha para dar uma série de palestras com a temática "emancipação intelectual da mulher" (LUTZ, 1920).

Já a conferência de 1922 foi planejada e executada em menos de três meses e, como destaca Branca Alves,

[...] em termos de estratégia, [...] a FBPF seguiu as pegadas da NAWSA, afastando-se cuidadosamente da má reputação das 'suffragettes'. [...] a NAWSA não se cansava de reiterar o pacifismo de sua estratégia, também como a FBPF, preocupada em manter incólume a sua reputação [...]. Havia uma constante preocupação em dar ao movimento uma aura de respeito através da posição social das associadas (ALVES, 1980, p. 132).

Teresa Marques destaca outra estratégia seguida por Bertha, aprendida de suas conversas com Catt: "que o feminismo podia avançar se fosse possível persuadir os homens de que as demandas femininas não constituíam ameaça à ordem social, e, acima de tudo, representavam uma inescapável evolução da civilização" (MARQUES, 2016, p.22). De modo que é também em busca de convencer os homens da legitimidade das demandas femininas que pode ser mais bem compreendida a feitura da conferência por Bertha e suas associadas.

Carrie Catt ajudou a elaborar a conferência no Rio de Janeiro, e, em outubro, apesar de elogiar o empenho das brasileiras e parabenizar a organização do evento, ela pede que sejam tomadas algumas providências específicas:

Disseram-me que há um lugar para onde todos os ricos e poderosos vão quando está muito quente e que reuniões ou conferências naquele lugar (que é cerca de uma hora ou mais do Rio de Janeiro) seriam capazes de pegar os mais influentes. Se uma reunião pudesse ser providenciada lá, seria satisfatório para nós. Deixamos o arranjo do tempo inteiramente à sua disposição, mas com o entendimento que teremos tempo para fazer um pouco de turismo para que possamos uma idéia real do Rio de Janeiro e suas condições e política antes de sairmos (Carrie Chapman CATT, 1922).

Nessa missiva ela também sugere que sejam tomadas providências para um encontro na cidade de Santos, porto de onde ela deveria partir, em janeiro, para Buenos Aires. Bertha seguiu, em parte, tais instruções uma vez que providenciou reuniões e palestras na cidade de Petrópolis, que ocorreram nos dias 27 e 28 de dezembro e na cidade de São Paulo, no dia oito de janeiro de 1923. Mariana Coelho destacou que Carrie

[...] veio ao Brasil encarregada de representar o Conselho Internacional de Mulheres - a maior organização feminina que existe no globo, fundada na América do Norte, e à qual estão federadas todas as associações congêneres, de todos os países. Carrie Chapman Catt é, repetimos, considerada a primeira líder da mulher, em todo o mundo (Mariana COELHO, 2002, p. 170).

A imprensa utilizou palavras elogiosas na cobertura do evento, destacando a iniciativa como "louvável", "memorável", "cordial e brilhante" além de exaltar que a conferência seria a responsável por dar "uma nota sensacional" à capital federal e que colocaria "o feminismo 
em boa marcha no Brasil". A chegada de delegadas estrangeiras para participar do evento também foi noticiada pelos jornais que deram destaque para nomes como os de Anna Castro Osório, de Portugal e Elisabeth Babcock, de New York (O PAIZ, 09/12/1922, p. 6). Também foi dado ênfase ao fato de que as mulheres estarem concorrendo com os homens por emprego, tanto que um jornal chegou a denominar tais mulheres como "adoráveis e adoradas inimigas" (O PAIZ, 12/12/1922, p. 3).

Desde a divulgação do evento já se percebe certa insistência em vincular a conferência a uma feição moderada. Carrie Catt foi apresentada ao público brasileiro como "a principal orientadora do movimento feminista internacional contemporâneo" (A NOITE, 19/12/1922, p. 6). E, a sua presença no evento, foi dado destaque como sendo a que traria "extraordinário brilho e repercussão no exterior ao congresso como será de grande utilidade no que respeita a uma sábia e moderada orientação para a ação futura" (O PAIZ, 17/12/1922, p. 5).

O apoio do governo também foi lembrado pela imprensa, que destacou a participação de delegadas indicadas pelos governos estaduais para participar do evento, tais como os governos de Pernambuco, Paraíba, Bahia, Sergipe, Pará, Santa Catarina, Amazonas, Rio Grande do Sul, Espírito Santo e Paraná, e entre elas, foi salientada a presença de Nair Coimbra, filha do vice-presidente da República (A NOITE, 18/12/1922, p. 1). O governo federal também nomeou representantes para prestigiar o evento bem como foram enviadas delegadas de várias entidades, tais como: a Cruzada Nacional contra a Tuberculose; o Centro Social Feminino; a Liga de Professores; a Cruz Vermelha; a Legião da Mulher Brasileira; a União dos Empregados do Comércio (A NOITE, 27/12/1922, p. 6). Também participaram do congresso 25 delegadas da Federação, 24 delegadas da Liga do Distrito Federal, 20 da filial paulista e duas da mineira além de homens de destaque na política como Lopes Gonçalves, Justo Chermont, Lauro Müller, Evaristo de Moraes e Estácio Coimbra, vice-presidente da República.

Carrie Catt, ao desembarcar no Rio de Janeiro, concedeu entrevistas para os jornais, destacando:

A nossa vinda tem por fim trazer a simpatia a essas trabalhadoras e a mensagem as mulheres sul americanas, das mulheres de todos os continentes, para que colaborem com elas, no movimento mundial em prol do progresso feminino [...]. Também esperamos interessar os homens que estão cultivando os bons aspectos do pan americanismo no auxílio das organizações femininas, pois devemos frisar que o movimento feminino não é um movimento da mulher contra os homens, mas um trabalho de conjunto feito pelos homens e mulheres de ideia que procuram promover o progresso geral. [...] viemos estimular tanto as conservadoras como as pessoas de ideias adiantadas, tanto os tímidos como os intrépidos, para tomarem parte neste movimento, no qual há margem para todos os diferentes tipos femininos (CORREIO DA MANHÃ, 19/12/1922, p. 3, grifos nossos).

Desde o princípio, a legitimidade e o reconhecimento das demandas do movimento feminista foram objeto de contestação e, ao se analisar as palavras de Carrie, percebe-se tal fato. Soihet, nesse sentido destaca: "tão assustadora [...] era [para os homens] a ideia de uma possível confusão nos papéis sociais, temerosos da perda de seu predomínio nas relações de poder entre os gêneros, que lançavam mão das estratégias mais variadas para manter o status quo" (SOIHET, 1996, p. 100, grifo no original). Assim, melhor se compreende os argumentos que eram evocados pelos antagonistas das feministas, que destacavam que elas queriam tomar o lugar dos homens, inverter os papéis de gênero, retirar as mulheres do lar e trazer o caos para sociedade. Para rebater tais argumentos, Carrie Catt reafirmou, mais de uma vez, durante sua estada no Brasil, que se devia interessar os homens 
para que eles lutassem pelos direitos femininos e proclamar que o feminismo não era contra os homens. ${ }^{4}$

Os temas tratados no evento priorizaram medidas e métodos práticos de trabalho e aperfeiçoamento nos campos de ação e interesse femininos e procuraram apontar a necessidade de melhorias na educação feminina, de se ter leis para proteger e resguardar o trabalho feminino, bem como as mães e a infância. Na conferência também foi dado destaque a tópicos relativos à emancipação política das mulheres. Os trabalhos foram divididos em comissões, assim denominadas: Instrução e Ensino; Carreiras e campos de atividades apropriadas às mulheres; Trabalho feminino; Direito da mulher; Assistência e proteção à mãe e à criança; Organização e O Papel da mulher na civilização. Em cada uma delas foram apresentados trabalhos destacando a participação feminina em todos os níveis de ensino, inclusive no ensino doméstico; palestras salientado o papel da mulher na saúde pública, na profissão de enfermeiras, de bibliotecárias e na aviação. Também foi abordado o papel da mulher na indústria, no comércio e no funcionalismo público, bem como apresentadas propostas de mudanças na legislação para proteger o trabalho feminino, além de temáticas inspiradas no Congresso Pan-americano, como a atuação feminina na manutenção da paz e nas relações internacionais de amizade.

O discurso de abertura deveria ter sido feito por Estácio Coimbra, que não pode comparecer, tendo sido substituído por Bertha Lutz. A imprensa transcreveu parte do arrazoado da presidente da FBPF que destacou:

Não é um interesse egoístico que as leva [as mulheres] a desfraldar a flamula das suas reivindicações na sociedade. O que a mulher deseja é colaborar com o homem na mesma obra de civilização e progresso, na grandeza mesma do Brasil e na segurança da sociedade brasileira. E por isso a mulher não esquecerá também o problema da educação, como base fundamental da sua independência, até as questões delicadas do internacionalismo (O IMPARCIAL, 20/12/22, p.7).

Cada seção de discussão foi pensada para se adequar aos parâmetros internacionais, bem como demonstram que as reivindicações femininas estavam concentradas no tripé educação-trabalho-voto. Os temas das palestras foram: o papel da mulher na higiene infantil e na saúde pública; o ensino da economia doméstica na Noruega e o papel da mulher na civilização. Tal escolha destaca uma das estratégias empregadas pela Federação que ajudaram a fixar a imagem de um bom feminismo praticado por elas, ou seja, um feminismo que daria destaque para a mulher como sendo responsável pelas crianças e pela casa, sempre garantindo que o papel feminino no seio familiar não seria prejudicado com o envolvimento no movimento organizado, mas sim, aprimorado, podendo ser percebido como um ponto nevrálgico de ałuação da FBPF. Em 1924, tal estratégia é amplamente explorada pela FBPF tal como se percebe em um memorial elaborado como forma de protesto ao projeto apresentado pelo deputado por Minas Gerais, Basílio Magalhães que, em novembro de 1924, solicitava o voto feminino apenas para mulheres alfabetizadas, maiores de 21 anos, com renda que lhe assegurasse a subsistência, se solteira ou viúva ou, se casada, com o consentimento do marido. No memorial se lê:

[...] os que combatem o direito de voto à mulher sustentam que a mulher se deve dedicar exclusivamente ao lar. É uma falta de lógica argumentar desse modo. O lar, a família, é uma célula do organismo social. Se a mulher exerce uma atuação preponderante sobre o lar, está preparada, por isso mesmo, para ter, como tem tido,

${ }^{4}$ Temas ainda em discussão no século XXI, tal como deixa explícito a plataforma da ONU Mulheres e a campanha "HeForSHE". 
uma ação salutaríssima nas questões que mais de perto interessam com a educação, proteção das mulheres que trabalham, das crianças abandonadas, da paz entre as nações, etc. [...] A mulher, sem descurar do seu lar, pode dedicar parte de sua atividade a obras de caridade, de proteção aos fracos, etc. que exigem um emprego de tempo maior do que o que tiver de conceder às reuniões políticas e às três ou quatro eleições anuais que tiver de comparecer [...] (apud COELHO, 2002, p. 164-167).

Os jornais cariocas fizeram versões diferenciadas da cobertura da conferência, das quais destaco, por exemplo, O Imparcial, que apontou os aspectos mais pitorescos do encontro salientando o fato de ser uma reunião de mulheres, assim

[...] o recinto destinado às congressistas tinha um brilho estonteante de 'toilletes' finas, de plumas, de vestidos, de sedas e sorrisos encantadores. Nos desvãos, nas passagens, nos corredores que levam à porta de saída e à secretaria, a mesma nota galante, a mesma graça, os mesmos sorrisos. Era bem um elegante congresso feminino (O IMPARCIAL, 20/ 12/1922, p. 7).

Por outro lado, o Correio da Manhã salientou as palestras da abertura do evento e, em especial, a de Bertha que, na ocasião destacou a importância da participação de Carrie Catt para o feminismo no Brasil, com as seguintes palavras:

[...] seguindo-a, seguiremos a orientação sã, boa, equilibrada que tem triunfado em todos os países. Colocando-vos ao seu lado chegamos a realização de ver o ideal do feminismo 'tal como é definido pela sra Catt' assegurar a colaboração da mulher no aperfeiçoamento das condições de vida não só para a mulher como para o homem e as crianças as condições e vida em geral. (CORREIO DA MANHÃ, 20/12/1922, p. 3).

O mesmo periódico também deu destaque para o discurso de Carrie Catt que, na ocasião, teria proclamado:

Houve uma época em que era considerada uma infelicidade pertencer ao sexo feminino, mas hoje não era mais assim. Quanto ao movimento feminino, é um aspecto necessário do desenvolvimento da época que atingira em sua plenitude o Brasil, como atingira em outros países. Não representa, entretanto, a reivindicação de direitos, mas a colaboração da mulher com o homem para o bem geral. Deus fez o homem e a mulher; criou a ambos e ambos são necessários à civilização, que não pode ser feita sem a colaboração do lar, da família, da igreja, do Estado, de todos os fatores, inclusive a mulher (CORREIO DA MANHÃ, 20/12/1922, p. 3, grifos nossos).

Bastos Portella, enviado para cobrir o evento, criticou o "brilho ofuscante [do] luxo, uma exibição acintosa de joias caras, de 'toilettes' ricas finas e vistosas" bem como deu ênfase ao que chamou de "balbúrdia" pois "as congressistas discutiam pelo prazer de não ficaram caladas". Segundo ele:

Alguma coisa [...] se pode apreender no ruidoso Congresso Feminino: desejam as feministas conquistar, integralmente, a mesma preponderância que o homem exerce na sociedade atual. Nesse particular, soube dispor as coisas com habilidade. E é assim que resoluções irrevogáveis foram assentadas, com o intuito senão de alijar o homem das bases em que se fixa, pelo menos de concorrer com ele na prática de todos os movimentos humanos compatíveis com a natureza e o forte espírito feminino. Os do sexo feio vão ficar, assim, - com a evolução das coisas - num plano inferior ao da mulher, numa submissa atitude de franca passividade social [...] Por isso, não ficaria fora de propósito perguntar-se as senhoras congressistas que tomaram parte da Conferência: 'Invertendo-se os papeis dos sexos, na sociedade - pois é a isso que as sufragistas nos desejam levar - quem viria a ser a ama de leite dos nossos filhos?' ( $O$ IMPARCIAL, 28/12/1922, p. 4, grifos nossos) 
Assim, de forma sutil ou explícita, alguns jornalistas procuravam reduzir a importância da Conferência Feminina a uma ruidosa reunião de ricas e desocupadas senhoras da sociedade que queriam concorrer com os homens, rebaixá-los a uma condição inferior e inverter os papéis dos gêneros. Como salienta Soihet, mais do que divertir o público, "percebe-se um aspecto perverso nessas insinuações, [...] a reiteração da comicidade na abordagem de suas reivindicações tende a difundir uma imagem em voga, acerca da falta de seriedade das preocupações femininas, ao contrário das masculinas" (SOIHET, 1996, p. 107).

No segundo dia de reuniões, o destaque foi a fundação da Aliança Brasileira pelo Sufrágio Feminino. Sua criação foi saudada como "uma data memorável na história do movimento feminino no nosso país" (O PAIZ, 21/12/1922, p. 5; O IMPARCIAL, 21/12/1922, p. 12), e ocorreu na sessão Direitos da Mulher com o intuito de se dedicar, unicamente, pela aprovação do voto feminino. Justo Chermont, autor do projeto que estava sendo analisado no Senado em prol do sufrágio feminino, foi homenageado nessa sessão, inclusive por Carrie Catt. A presidência da Aliança foi concedida para Isabel Chermont, esposa do senador, sendo Bertha designada como secretária. A Revista Feminina assim descreveu o evento:

Surge em uma das reuniões da grande conferência do Rio a Aliança Brasileira pelo Sufrágio feminino, filiada à Aliança Internacional e é de se esperar que essa nova agremiação, aliada as demais, se compenetre do verdadeiro fim que almeja a brasileira, isto é, um feminismo prático, católico e porque não dizer, um feminismo brasileiro, de acordo com os nossos hábitos, os nossos costumes e que garanta a ela a realização dessa igualdade tão almejada (REVISTA FEMININA, 01/1923, p. 3).

Em fevereiro de 1923, Bertha indicava a abertura de duas filiais da nova agremiação, uma no Rio de Janeiro e outra em São Paulo (LUTZ, 1923). A criação de uma associação para lidar, de forma exclusiva, com o sufrágio feminino, foi influenciada pela trajetória do movimento organizado feminino sob a liderança da NAWSA. Ao retornar para o Rio de Janeiro, Bertha já havia declarado a intenção de fundar tal associação, como disse para Carrie: "a Associação Sufragista será iniciada em breve". Nessa carta, Bertha a questiona se seria adequado aceitar homens como associados, e, caso a resposta fosse positiva, em qual função, pois: "Alguns dos homens influentes [do Brasil] são muito favoráveis [à questão do sufrágio feminino] e a opinião deles conta muito [...]" (LUTZ, 1922). Recebendo resposta afirmativa de Catt, Bertha chegou a convidar alguns políticos, contudo a situação se deteriorou a tal ponto que a Aliança teve seu fim decretado, menos de dois anos da sua fundação. Em 1924, Bertha relatou, em carta enviada para Carrie Catt, que estava enfrentando problemas com a Aliança, evocando a sua inatividade, divergências entre os participantes e uma incompreensão do papel e da vinculação direta com a Aliança Internacional. Assim, Bertha comunicou a extinção da entidade, relatando: "A sra Chermont depois de manter a Aliança pelo Sufrágio Feminino inativa por mais de um ano, finalmente devolveu o dinheiro que estava em sua posse e propôs a fusão de sua associação com a nossa, o que tivemos que aceitar" (LUTZ, 1924).

O dia 22 de dezembro concentrou as últimas reuniões dos grupos de trabalho. A última palestra intitulada $O$ papel da mulher na civilização foi ministrada por Carrie Catt. A sessão de encerramento foi presidida por Lauro Muller que, na ocasião, aconselhou

[...] as entusiásticas reivindicadoras dos direitos políticos da mulher, que não esperem que lhes venham dar, mas que os conquistem pela ação, pelo trabalho, demonstrando aos homens que bem merecem esses direitos pela educação que alcançarem e pelo seu próprio valor (O PAIZ, 24/12/1922, p. 6) 
Bertha, em 1963, ao relatar o que ocorreu na Conferência de 1922, salientou para João Batista Cascudo Rodrigues:

Foi o Senador Lauro Muller que nos lembrou [...] que a Constituição não proibia o voto, ajuntando que os homens eram como carneiros. Se a Federação Brasileira pelo Progresso Feminino conseguisse que um governo estadual interpretasse a Constituição de modo certo, os outros governos a seguiriam (LUTZ apud João Batista Cascudo RODRIGUES, 1982, p. 161).

Alguns anos mais tarde, ao descrever a conferência para Branca Alves, Bertha fez questão de salientar que o voto estadual havia sido tratado naquela ocasião, bem como que o senador Muller teria afirmado: "os homens são como carneiros. Um vai na frente, os outros vão atrás. As Sras têm que furar a cerca. Procurar um governador de Estado que fure a cerca, que dê o voto às mulheres no Estado dele, e atrás disso vão todos os Estados da Federação" (ALVES, 1980, p. 114-115). Trago tal trecho para ressaltar a reinterpretação que Bertha fez do passado da FBPF com fins de o ressignificar para deixar mais clara a imagem da instituição que ela pretendia perpetuar. Essa forma de rememorar e recontar o passado evidencia as estratégias empregadas por Bertha na divulgação posterior das suas lutas pela emancipação feminina, e pode ser compreendida como uma forma de enquadramento da memória tal como destacou Michael Pollak (1989) em seus estudos. Sobre o voto regional, em 1925, ela declarava: "sou contrária à concessão inicial do voto municipal, pois está demonstrado constituir esta praxe mais um empecilho do que um impulso à concessão interior dos direitos na sua plenitude nacional" (LUTZ, 1925). Contudo, dois anos mais tarde em 1927 - ela propagava que "o melhor de tudo é uma lei estadual, em grau menor [e] permissão ao alistamento fazendo conhecer opinião favorável, o mínimo que não impeça as mulheres de se alistarem" (LUTZ, 1927). A mudança na postura de Bertha pode ser creditada ao fato de que, desde 1926, quando da candidatura de Juvenal Lamartine, um dos políticos aliados da FBPF, para o governador do Rio Grande do Norte, uma de suas promessas de campanha era estender o alistamento eleitoral para as cidadãs do seu estado. Tais atos podem ter feito com que, quarenta anos após, ao rememorar esses eventos, Bertha os tenha contado como desejava que fossem lembrados.

Em março, a Revista Feminina passa a criticar o evento, colocando sob suspeita a participação de Catt, reclamando que aqui tinha vindo para "pregar um feminismo, todo de seu país, todo extremo e audácias, mais ou menos inspirado em princípios de protestantismo, profundamente antagônico com as nossas tradições morais e étnicas" (REVISTA FEMININA, 03/1923, p. 3). Tal crítica pode ser compreendida tendo em vista que, desde que começou a expandir a Federação, Bertha se deparou com problemas na filial paulista, desencadeados por alguns setores da Igreja Católica que vinham fazendo campanha contra o mau feminismo (KARAWEJCZYK; Tatiana Vargas MAIA, 2016). Na década de 1920 ocorreu um intenso envolvimento dos católicos na política, desencadeado pela perspectiva do episcopado de que

[...] a crise do país só era aparentemente política ou socioeconômica, ela era fundamentalmente ética. Por conseguinte, restaurando os princípios morais no país, através de uma presença significativa da Igreja Católica, o país encontraria automaticamente o caminho da ordem e da prosperidade (Riolando AZZI, 1994, p. 50).

Com o intuito restaurar os princípios morais no país a Igreja Católica passou a convocar as mulheres para fazerem parte de Ligas de Senhoras Católicas que estavam sendo constituídas em todo o país. Nestas, a lgreja, sob a alcunha de um feminismo cristão pretendia resguardar as brasileiras de uma má orientação e da influência de outras religiões. 
Entre os novos deveres da mulher, propostos pela Igreja, estavam elencados, em ordem de importância: a família, o trabalho, a escola leiga e o campo legislativo. Como a Igreja estava ciente que o mundo do trabalho se apresentava como uma questão imanente à nova mulher do século XX, ela - como instituição - procurava reverter o foco da emancipação para o seu domínio, procurando definir os rumos que esta emancipação deveria tomar, sem negar os avanços que já se mostravam inexoráveis.

Os problemas enfrentados com a lgreja Católica ainda encontrariam eco no ano de 1924, quando Bertha creditava ao "ciúme, calúnia, estupidez e má compreensão" o fato da sua organização - a FBPF - estar sendo confundida com uma associação anticatólica ou como "uma Liga de protestantes" (LUTZ, 1924). Sobre o impasse vivenciado com a Igreja, Bertha também busca o auxílio de Carrie Catt, sendo aconselhada a não entrar em conflito, pois o Brasil, segundo a sua perspectiva, "é um país católico e vai continuar assim. [...]. Agora que as mulheres votam em países católicos, em grande parte eu acredito que você vai descobrir que, mais cedo ou mais tarde, a lgreja Católica vai apoiar o sufrágio para a mulher em outras terras" (CATT, 1925). Bertha, a partir de então, passou a demonstrar uma atitude conciliatória para com a lgreja, buscando mesmo uma aproximação com a instituição.

\section{Considerações Finais}

Bertha Lutz teve um papel de destaque na luta em prol da emancipação feminina no Brasil, sendo a responsável por articular um grupo para fazer pressão junto ao governo, para aceitar as suas demandas. Ela tinha grande capacidade de articulação, podendo esta ser apreciada na fundação da FBPF e na sua primeira conferência. O grupo formado por ela era composto por mulheres proativas, que tiveram que tomar decisões estratégicas para que sua luta não fosse hostilizada pelos homens que ocupavam os cargos de poder, responsáveis por mudar as leis do país.

Os temas escolhidos para serem debatidos na conferência denotam a forma como a questão da emancipação feminina estava sendo pensada pelo grupo, bem como expõem as estratégias utilizadas e que acabaram por consolidar a imagem de representantes do "bom" feminismo no Brasil. Nas deliberações da conferência percebe-se que elas almejavam conseguir um lugar no espaço público, mas tendo o cuidado de assegurar que tal conquista não afetaria o papel da mulher no seio familiar. Elas procuravam novos espaços de socialização e, para que suas demandas fossem aceitas, apresentaram o papel feminino como complementar ao do homem. O tom de conciliação e moderação da Federação pode ser melhor compreendido se levarmos em conta que era uma tática para sensibilizar os homens nos cargos de poder a aceitarem suas demandas.

Bertha, à frente do movimento organizado, sempre destacava que procurava orientar as mulheres para seguir o "bom feminismo", tal argumento sendo empregado desde 1922. Tal estratégia, aprendida por Bertha nas suas deliberações com o movimento feminino internacional, foi amplamente apresentada para o público durante a Conferência pelo Progresso Feminino, como destacado ao longo desse artigo. Mas nem tudo foram flores no caminho da FBPF e os mesmos periódicos que elogiaram a conferência também a criticaram mostrando que o caminho para a mudança de consciência e dos preconceitos era (e é) árduo e longo.

\section{Referências}

A NOITE. Rio de Janeiro, 02/01/1922, p. 1.

A NOITE. Rio de Janeiro, 05/08/1922, p. 1-2.

A NOITE. Rio de Janeiro, 18/12/1922, p. 1.

14 Revista Estudos Feministas, Florianópolis, 26(2): e49845 
A NOITE. Rio de Janeiro, 27/12/1922, p. 6.

ALVES, Branca Moreira. Ideologia e Feminismo. A luta da mulher pelo voto no Brasil. Petrópolis: Vozes, 1980.

ARQUIVO NACIONAL, FUNDO FBPF, Arquivo Privado 46, Seção Administração, Série correspondências, Série voto feminino.

AZZI, Riolando. A Neocristandade: um projeto restaurador. São Paulo: Paulus, 1994.

BIROLI, Flávia. "O Público e o Privado". In: MIGUEL, Luís Felipe; BIROLI, Flávia (Orgs). Feminismo e Política. São Paulo: Boitempo, 2014. p. 31-46.

CATT, Carrie Chapman. Carta para Bertha Lutz. Arquivo Nacional - Fundo FBPF - Documentos Privados, Seção Administração, Correspondências, cx. 9, pac. 1, dos. 7, original em inglês, 3/10/1922.

Carta para Bertha Lutz. Arquivo Nacional - Fundo FBPF - Documentos Privados, Seção Administração, Sério Voto Feminino, cx. 29, pc 3, v. 3, original em inglês, 8/01/ 1925.

COELHO, Mariana. A Evolução do Feminismo. Subsídios para a sua história. ( $1^{a}$ ed. 1933). Curitiba: Imprensa Oficial do Paraná, 2002.

CONTROLE de Associados, Arquivo Nacional - Fundo FBPF - Documentos Privados, Subseção Controle de associados, cx 64, pc 3, dos 1, v. 5, 1934

CORREIO DA MANHÃ. Rio de Janeiro, 18/02/1922, p. 3.

CORREIO DA MANHÃ. Rio de Janeiro, 19/12/1922, p. 3.

CORREIO DA MANHÃ. Rio de Janeiro, 20/12/1922, p. 3.

DUBOIS, Ellen Carol. "The Radicalism of the woman suffrage movement". In: DUBOIS, Ellen Carol. Woman suffrage and women's rights. New York: New York University Press, 1998. p. 30-42.

HAHNER, June. Emancipação do Sexo Feminino. A luta pelos direitos da mulher no Brasil, 1850-1940. Florianópolis: Mulheres; Santa Cruz do Sul: EDUNISC, 2003.

HINO Feminista. Arquivo Nacional - Fundo FBPF - Documentos Privados, Seção Administração, Produção de Terceiros, 1922.

KARAWEJCZYK, Mônica. As filhas de Eva querem votar: dos primórdios da questão à conquista do sufrágio feminino no Brasil (c.1850-1932). 2013. Tese (Doutorado em História) - Programa de Pós-Graduação em História, Universidade Federal do Rio Grande do Sul, Porto Alegre, Rio Grande do Sul, Brasil.

KARAWEJCZYK, Mônica; MAIA, Tatiana Vargas. "A Igreja Católica e o voto feminino no Brasil - uma questão de poder e influência" Coisas do Gênero. São Leopoldo, v. 2, n. 1, p. 90104, jan./jul. 2016.

LEITE, Miriam Lifchitz Moreira. Maria Lacerda de Moura. Uma feminista utópica. Florianópolis: Mulheres; Santa Cruz do Sul: EDUNISC, 2005.

LOBO, Yolanda. Bertha Lutz. Recife: Fundação Joaquim Nabuco, Massangana, 2010.

LUTZ, Bertha. Carta para Avelina Souza Salles, Arquivo Nacional - Fundo FBPF - Documentos Privados, Seção Administração, Correspondências, cx 9, pc 1, dos 11, 7/11/1921.

LUTZ, Bertha. Carta para Carrie Chapman Catt, Arquivo Nacional - Fundo FBPF - Documentos Privados, Seção Administração, Correspondências, cx 29, pc 3, vol 3, original em inglês, [11/11/1924].

LUTZ, Bertha. Carta para Carrie Chapman Catt, Arquivo Nacional - Fundo FBPF - Documentos Privados, Seção Administração, Correspondências, cx 8, pc 1, dos 3, original em inglês, 23/08/1922.

LUTZ, Bertha. Carta para Harriet Chalmers Adams, Arquivo Nacional - Fundo FBPF Documentos Privados, Seção Administração, Correspondências, cx 8, pc 1, dos 3, original em inglês, 18/12/1920. 
LUTZ, Bertha. Carta para Miss Anna Wickesett, Arquivo Nacional - Fundo FBPF - Documentos Privados, Seção Administração, Correspondências, cx 5, v. 17.2, 27/02/1923.

LUTZ, Bertha. Carta para Mietta Santiago, Arquivo Nacional - Fundo FBPF - Documentos Privados, Seção Administração, Correspondências, cx 29, pc 3, vol 3, 18/09/1925.

LUTZ, Bertha. Carta datilografada incompleta sem destinatário, Arquivo Nacional - Fundo FBPF - Documentos Privados, Seção Administração, Correspondências, cx 17, pc 2, dos 2, [1927].

LUTZ, Bertha. Carta para Mariana Coelho, Arquivo Nacional - Fundo FBPF - Documentos Privados, Seção Administração, Correspondências, maço m, 10/1 1/1925.

MARQUES, Teresa Cristina de Novaes. Bertha Lutz. Brasília: Edições Câmara, 2016.

MIGUEL, Luís Felipe; BIROLI, Flávia (Orgs). Teoria Política Feminista: textos centrais. Vinhedo: Horizonte, 2013.

O IMPARCIAL. Rio de Janeiro, 04/08/1922, p. 3.

O IMPARCIAL. Rio de Janeiro, 12/05/1925, p. 5.

O IMPARCIAL. Rio de Janeiro, 20/12/1922, p. 7.

O IMPARCIAL. Rio de Janeiro, 21/12/1922, p. 12.

O IMPARCIAL. Rio de Janeiro, 28/12/1922, p. 4.

O PAIZ. Rio de Janeiro, 11/1 1/1921, p. 6.

O PAIZ. Rio de Janeiro, 30/08/1922, p. 6.

O PAIZ. Rio de Janeiro, 09/12/1922, p. 6.

O PAIZ. Rio de Janeiro, 12/12/1922, p. 3.

O PAIZ. Rio de Janeiro, 17/12/1922, p. 5.

O PAIZ. Rio de Janeiro, 21/12/1922, p. 5.

O PAIZ. Rio de Janeiro, 24/12/1922, p. 6.

PATEMAN, Carole. "Críticas Feministas à Dicotomia Público/Privado". In: MIGUEL, Luís Felipe; BIROLI, Flávia (Orgs). Teoria Política Feminista: textos centrais. Vinhedo: Horizonte, 2013. p. 55-79.

PERROT, Michelle. Os excluídos da história: operários, mulheres e prisioneiros. Rio de Janeiro: Paz e Terra, 1988.

PINTO, Céli Regina Jardim. Uma história do feminismo no Brasil. São Paulo: Fundação Perseu Abramo, 2003.

RAGO, Elisabeth Juliska. Outras falas. Feminismo e medicina na Bahia (1836-1931). São Paulo: Annablume, Fapesp, 2007.

REVISTA DA SEMANA. Rio de Janeiro, ano XIX, n. 47, 28/12/1918, p. 19.

REVISTA FEMININA. São Paulo, ano I, n. 104, 01/1923, p. 3.

REVISTA FEMININA. São Paulo, ano X, n. 106, 03/1923, p. 3.

RODRIGUES, João Batista Cascudo. A Mulher Brasileira. Direitos políticos e civis. 2. Ed. Rio de Janeiro: Renes, 1982.

ROWBOTHAM, Sheila. A Century of Women. The history of women in Britain and the United States. London: Viking, 1997.

SCOTT, Joan Walach. A cidadã paradoxal. As feministas francesas e os direitos do homem. Florianópolis: Mulheres, 2002.

SOIHET, Rachel. "Mulheres em busca de novos espaços e relações de gênero". Acervo Revista do Arquivo Nacional. Rio de Janeiro, v. 9, n. 01/02, p. 99-124, jan./dez. 1996.

SOIHET, Rachel. O Feminismo Tático de Bertha Lutz. Florianópolis: Mulheres; Santa Cruz do Sul: EDUNISC, 2006. 
[Recebido em 31/03/2017, reapresentado em $23 / 11 / 2017$ e aprovado em 16/02/2018]

Feminism in Good Gait in Brazill Bertha Lutz and the Conference for Female Progress Abstract: The purpose of this article is to describe and analyze the initial steps of the women's association founded by Bertha Lutz, the Brazilian Federation for Women's Progress, and its first conference occurring in the year 1922. Adopting a case study methodology, we present by both that ended up consolidating an image of representatives of "good" feminism in Brazil. Keywords: Bertha Lutz; Conference for Women's Progress; Feminism

Mônica Karawejczyk (karawejczyk@gmail.com) é licenciada, bacharel, mestre e doutora em História. Tem se dedicado aos estudos do processo que levaram a conquista do sufrágio no Brasil desde a época da graduação na UFRGS. Em 2013 fez parte da primeira turma de pesquisadores residentes da Fundação Biblioteca Nacional com a pesquisa intitulada "Mulher deve votar?" De 2015 a 2016, professora colaboradora do PPGHistória PUC-RS e bolsista PNPD-Capes na mesma instituição. 